\title{
Higher education students' experiences of digital learning and (dis)empowerment
}

\author{
Cristina Costa \\ Department of Education and Childhood, University of the West of England, UK
}

Mark Murphy

Robert Owen Centre for Educational Change, University of Glasgow, UK

Ana Lucia Pereira

Department of Mathematics and Statistics, State University of Ponta Grossa, Brazil

Yvette Taylor

School of Education, University of Strathclyde, UK

\begin{abstract}
This paper focuses on learning practices in higher education in relation to a digital participatory culture. Using key principles of critical education, the research set out to explore higher education students' sense of agency online - or lack of it -as part of their formal learning practices. The research found that although students were proficient Web users, they did not exercise their learner agency beyond what they assumed to be expected of them, thus evidencing the stability of their learning habitus in relation to the learning conventions associated with the academic field. Perhaps more surprisingly, however, is students' perception of the Web not only as a space of student participation, but also as a space of student surveillance. Such perceptions constitute real obstacles to meaningful participation as a form learning.
\end{abstract}

\section{Introduction}

Since the advent of the read and write Web (O’Reilly, 2005), a rhetoric of empowerment and participation has been linked to formal education (Selwyn, 2011). This has been particularly reflected in the literature of learning technology. In the context of liberal forms of education, it is relevant to imagine the Web as an instrument of educational change because of the lower barriers it provides for user engagement. These observations have often been translated into assumptions of the Web as an appropriate space for autonomous learning and authentic learning contexts, where agents can exercise their power and experience with a high degree of freedom as learners and informed citizens (see, for example, McLoughlin, 2013). Online learning has also been connected to digital culture practices (Miller, 2011) that rely heavily on individuals' creation of content and contribution of ideas as forms of participation.

While it can be claimed that the Web has affected the social world in general and created spaces for the self-organisation of knowledge networks (Castells, 2012), it is less clear how it impacts individuals' formal educational practices within the boundaries set by educational institutions. This is not to say that research on the integration of technology in the classroom is not abundant. Yet, it more often than not reports on its advantages or disadvantages rather than elaborating on how pedagogical practices are construed in relation to the Web. Much of the focus so far has been on pedagogical approaches that are regarded as suitable to the implementation of digital education. These encompass student-centred approaches, forms of collaboration and personalisation of learning that aim to recapture the legacies of critical thinkers such as Freire (1968/1970) and Illich (1971) in a digital context (see de Freitas \& Jameson, 2012). The interpretation here is that digital technology is inherently transformative. Additionally, there is a plethora of publications on student expectations of classroom teaching with technology (e.g., Duncan-Howell, 2012; Waycott, Bennett, Kennedy, Dalgarno, \& Gray, 2010). This perspective derives from the need to connect education to the "real world" and bridge students' day-to-day experiences in the digital with their educational activity. Yet, very little research seems to elaborate on the impact of such educational proposals on learners' actual learning practices.

It is with these observations in mind that we set out to examine students' actual learning practices not only in relation to their use of the Web for their learning, but also to the broader set of assumptions about the 
transformative nature of technology. In order to fulfil the purpose of developing a critical understanding of the interplay between higher education students' digital practices and their approaches to learning, a threeyear study involving higher education students was conducted. The article explores participants' sense of autonomy and agency - or lack of it - in the context of a digital participatory culture applied to formal learning practices.

This introduction is followed by a review of the main principles concerning digital educational approaches, especially those related to digital participatory practices. The methodology underpinning the study is then presented and the findings of the research analysed. Finally, we discuss the findings in light of Pierre Bourdieu's conceptual framework of practice (see, for example, Bourdieu, 1977, 1990) as they cast a critical perspective on digital practices.

\section{Digital education: participation as learning}

Critical conceptions of learning and teaching had already been extensively developed before the advent of the Web, especially through pedagogical paradigms that place an emphasis on participation, communication and contextualisation of learning and where the learner is at the centre of transformative change (Giroux, 1988). Inherent to these principles is an intention to change power relations amongst agents, especially through the emancipation of those who are, in Freire's (1968/1970) words, living and learning under a culture of domination. Critical pedagogies can thus be understood as a response to social struggles and injustices that are reproduced by education systems that regard learners simply as consumers of information.

It is in this regard that Freire (1968/1970) launched his critique against what he named "banking education"; a passive form of learning that eschews student “conscientização” (p. 74), in essence, critical consciousness. To counteract this trend, Freire proposed a problem-posing type of education that is dialogical in nature (Freire, 1968/1970, p. 84). Whereas banking education obstructs creative inputs by taming individuals’ actions and avoiding negotiation of meaning, problem-posing education regards individuals' creations and contributions as meaningful acts of learning. The objective of problem-posing education is that of critically engaging the learner in the analysis of the social reality that surrounds him/her so that s/he can act on it. As a form of empowerment, problem-posing education emphasises not only critical agency, but also active and democratic citizenship.

The proposal of such an archetype of education is not very different from that suggested in the digital education literature (e.g., Sharpe, Beetham, \& de Freitas, 2010). The Web as an apparent unrestricted space of consumption and production of information opens up new opportunities for collective intelligence and congregation (Wenger, White, \& Smith, 2009), where agents are expected to be in charge of their own learning. Behind this celebration of agency is a suggestion of a form of empowerment. Online, however, this enactment of agency is dependent on individuals' own dispositions to participate in such digital spaces. A participatory culture is epitomised by acts of creation and sharing, with individuals acting as both contributors and supporters of others' creations (Jenkins, Ito, \& boyd, 2016). The ethos of a participatory culture online is thus as much an individualised practice as it is a collective endeavour.

There is no doubt that both critical education and the digital participatory culture seek the democratisation of knowledge and the emancipation of the learner. Nonetheless, it is crucial not to confuse the opportunities the Web provides for agency with aspirations of equal participation and status amongst participants. Even though the Web has been developed with a set of democratic values in mind, a "truly participatory culture" is far from being established online (Jenkins et al., 2016, p. 182) as structural struggles and inequalities are often mirrored in the digital world, with dominant groups commonly taking centre stage in this process. Yet, there are ways to respond to this type of domination. As Jenkins et al. (2016) emphasise, "the more participatory contexts we create, the more opportunities we create for meaningful participation” (p. 182).

\section{The logic of digital practices}

Just like Freire (1968/1970), Bourdieu and Passeron (1964/1979, 1990) too provided a critique to the formal education system of their country. These critiques can be, and have been, applied to other (inter)national realities. Freire (1968/1970, 1985) appraised the Brazilian educational system as dehumanising and 
Bourdieu and Passeron (1990) understood French education as a reproductive scheme representative of the taste and habitus of the leading classes. Nonetheless, their perspectives on what role education can play in the liberation of the learner diverged. Freire (1985) regarded education as the answer to the issues derived by the educational system itself in that education has the potential of emancipating the individual. Bourdieu and Passeron (1990), on the other hand, deemed education as a threat to genuine individual autonomy and agency. What they all agreed on is that the structure of formal education is indeed a form of domination, more concretely, a form of oppression and symbolic violence (Burawoy \& Holdt, 2012).

The Web as an alternative space for learning has often been characterised as inherently democratic, because of the availability of tools and approaches that are available to citizens. Its rather unregulated structure allows for creative practices and different types of membership and contribution which in essence is what characterises a digital participatory culture (see Jenkins, 2009). Although the combination of the Web and education has the potential to generate different contexts for learning (Dias de Figueiredo, 2005), it is not a given that the Web can serve education in transformative ways. Digital participatory learning as a form of liberation is as much dependent on what the Web enables and it is on the attitudes and values of the agents that learn in those spaces (Costa \& Harris, 2017). It is in this sense that it is important to evaluate the "inflated rhetoric" that surrounds the digital and its connection to education (Buckingham, 2013).

For the purpose of this research, we borrow from the work of Bourdieu (1990) key concepts, especially field, habitus and doxa to operationalise the Web as a social space and a field of practice. Following Bourdieu's writings, we work on the interpretation that the perception of any given social space is a "product of a double structuring” process (Bourdieu, 1989, p. 20) encompassing objective and subjective constructions of reality; one in which the properties attributed to agents and the schemes of perception and appreciation that define them are ever present in the spaces in which they interact (Bourdieu, 1989), sometimes in more conscious ways than others. As a new locus of action, the Web represents an additional, sometimes alternative, space in which "new forms of power, status and control emerge [and from which] new forms of inequality” (Jenkins et al., 2016, p.12) can derive. Even so, the Web does not represent an institutionalised structure with recognised norms. In fact, at first sight, the Web may present itself as a free social space able of accommodating different cultural practices and its distinctive agents. This diversity is a reflection of the different capitals - social, economic, cultural and symbolic - that individuals bring to the digital sphere as their embodied habitus. This, however, is not to say that the Web is devoid of a structure, but rather that the configuration of practices online may seem less organised because they are not institutionalised. Individuals' practices, on the other hand, may already be entrenched by institutional rules. Such observations can lead to interpretations of the Web as a space with a higher level of freedom to act when compared to other spaces of practice that are shaped by a regulatory hand.

Individuals' practices - digital or not - are, to a great extent, a reflection of the dispositions, or the habitus they "carry across the varied contexts of their daily lives" (Bennett \& Maton, 2010, p. 326). This understanding of habitus as accumulated and transferrable dispositions from and to different social spaces is important to the understanding of higher education students' learning practices online as it places the students in relation to the different learning contexts that shape their academic experience. It can be said that the social world is "constructed in different ways according to different principles of vision and division” (Bourdieu, 1989, p. 19). For example, the role of the Web and digital participatory culture can be approached differently by educators and students, thus creating not only social but also intellectual distances between the different groups of agents.

The understanding of individuals' own logic of practice can be further advanced by the application of the concept of doxa "as the embodiment of beliefs belonging to a field of practice" (Costa \& Murphy, 2016, p. 52), that is, as uncontested habitus. Doxa is herein a pertinent lens of observation when studying which digital practices students consider relevant to their education and which ones they reserve for other realms of their lives. Research on digital dissonances (Hrastinski \& Aghaee, 2011) has reported on the problematic of transferring digital practices from one social space to another. Students often do not associate their engagement with the Web with formal education. This unconscious demarcation between digital practices exercised in formal education and those practised elsewhere (Clark, Logan, Luckin, Mee, \& Oliver 2009) is a clear indication that the digital world enjoys different statuses in different fields of action. The next section presents a summary of the research methods. It is followed by the analysis and discussion of the findings. 


\section{The study}

For the purpose of this paper, we explored the learning practices of higher education students enrolled in a module titled "Living, Learning and Working on the Digital Economy" offered in a university in the United Kingdom. The module ran once a year for a period of 3 years and was taken by 87 second-year students enrolled in degrees across the humanities and social sciences. Sixty-four of the students enrolled in the module consented to being part of the study.

In order to conduct empirical work on students' learning practices online, an ethnographic action research approach was conducted with regards to the design and implementation of the module in question. The module was organised to provide students with relevant content about the Web, but also, and above all, encouraged students to adopt learning approaches that stimulate their critical engagement and participation with their studies.

The combination of ethnography (a way of understanding cultural practices) and action research (a form of inquiry to nurture new practices) (Tacchi, Slater, \& Hearn, 2003) fulfilled the objective of developing an iterative research approach (Tacchi, Foth, \& Hearn, 2009, p. 4). The choice for an ethnographic action research design derived from the importance of working within the realm of reflective practice with both the researchers and the researched. Reflection was a crucial component for the research as it allowed exploration of the circumstances in which practices occurred and how practices could be improved. Reflective practice is a common feature of online participation; a form of recording and sharing experiences and establishing a presence online. The implementation and study of the module took place in two complementary phases that were repeated and refined every time the module ran.

The first phase consisted in embedding the features of the digital culture into the curriculum to promote some of the principles of critical education, especially those regarding learners' autonomy. This led to the development of a blended learning format with a strong emphasis on the development of online practices as forms of participation. Learning activities proposed in the module were thus intrinsically linked to and dependent on students' online contributions. The purpose was to give visibility to students' productions as acts of learning and thus foster proactive approaches to learning via the Web. Drawing on the work of Jenkins, Ito, and boyd (2009) and Miller (2011), we designed a range of learning activities that aimed to engage participants in digital participatory and dialogical tasks, as depicted in Table 1.

Table 1

Digital participatory culture features and their connection to curricular activities

\begin{tabular}{ll}
\hline $\begin{array}{l}\text { Digital participatory } \\
\text { culture features }\end{array}$ & Critical pedagogy learning activities \\
\hline Creation & - $\begin{array}{l}\text { Proposals of learning activities (and assessment) that require } \\
\text { learners' production of content via their blogs and other platforms, } \\
\text { such as video logs and animations }\end{array}$ \\
- & $\begin{array}{l}\text { Design of sessions where students could present and discuss their } \\
\text { creations with their peers and wider audiences }\end{array}$ \\
- & $\begin{array}{l}\text { Built-in peer-comment as part of their blog reflective activities as a } \\
\text { form of dialogical learning (and assessment) }\end{array}$ \\
- & $\begin{array}{l}\text { Encouragement of sharing practices and resources via networks } \\
\text { such as Twitter as part of their learning process }\end{array}$ \\
- & $\begin{array}{l}\text { Proposals of learning opportunities across different spaces and } \\
\text { networks, by encouraging students to participate in relevant } \\
\text { knowledge networks online }\end{array}$ \\
- & $\begin{array}{l}\text { Encouragement of networking practices in and beyond the } \\
\text { classroom via network sites such as Twitter and established } \\
\text { hashtags }\end{array}$ \\
\hline
\end{tabular}

The second phase of preparing the research consisted in finding methods which would allow us to access students' digital learning practices. Following Tacchi et al.'s (2009) work, we adopted a participant observation position within the research project as a form of continuously reflecting on and recording what was being observed. Field notes were taken on a regular basis, as part of the observations, thus becoming a 
form of documenting what was observed and also of developing a research routine that would keep us constantly engaged with the project not only as educators, but also as researchers (Angrosino, 2007).

Participants were asked to keep a reflective blog and a Twitter account as part of their participation in the module. The blog served to record and reflect about their own practices and approaches to learning on the digital, while Twitter - via a specific hashtag - was used as a channel of participation for sharing of ideas, resources and conversations related to the module.

Students' online participation became valuable research data to the project as it captured participants' activity, voices and opinions of the module; at the same time, it provided evidence of their digital learning practices. In this regard, their online participation became a core focus of researchers' observational activity and recorded through researchers' field notes.

Research ethics permission to conduct this research was requested and granted by the ethics committee. The researchers ensured that all research participants featured in the study were informed of the intent of the project and that participation in the research project was subject to participants' informed consent. Additionally, we were conscious that examining participants' public digital participation was complex as often the understanding of publicness, or privacy online, for that matter, does not necessarily coincide with the technical settings offered by the platforms in use (Grønning, 2015). As a way to overcome this issue, it was decided that additional forms of data collection were necessary so that the data used for publication could be completely anonymous without risk of traceability to the source or author. The decision led to the development of an open-ended questionnaire where participants could report their experiences both privately and anonymously. Although questionnaires often provide limitations with regards to capturing detailed information, as they do not offer a chance of asking follow-up questions, they can be effective instruments of data collection in cases where identification of source is seen as a delicate matter. The choice of pursuing questionnaires instead of interviews was also motivated by the fact that questionnaires would allow participants to remain anonymous to the researcher/tutor. This had the purpose of allowing participants to feel they could take a candid approach to their answers by dissociating the role of the researcher from that of the tutor.

For the analysis of the research data, a thematic approach within an interpretive stance was adopted. This allowed us to explore patterns, consistencies and contradictions across the information collected. The findings of the data collected are analysed in the section below.

\section{Findings}

Two key findings surfaced regarding students' engagement in and perceptions of the Web for educational purposes. The first finding shows that students were ambivalent about the ways they should participate on the Web as part of their enrolment in the module being researched. The second key finding relates to students' formal engagement with the Web as both a space of participation and a form of exposure.

Although participants often reported on the benefits of online communication as a form of free expression, they also reflected on the vulnerabilities they felt about making their participation visible on the Web. We depict these aspects below through an analysis of the findings and related discussion. We draw on direct quotes from the research participants as evidence of research findings. As a form of preserving participants' confidentiality, we only use quotes from anonymised and untraceable sources, as, for example, those extracted from the anonymous questionnaires, instead of other forms of communication that were open to the public and can be traced to its user, as, for example, tweets. In such case, researchers' field notes have been used instead.

\section{Ambivalence and digital learner autonomy}

In general, participants seemed to enjoy the proposed learning approaches, especially because of the novelty that is associated with learning on the Web, as the example quotes suggest:

I enjoyed being able to get in touch with others via the hashtag and I thought creating our own blog was unique. (Anonymous questionnaire) 
I enjoyed the fact that so many components of the module were online.... [and] writing the blog posts as they are a way of expressing our opinions on different topics which we don't usually get the opportunity to do in other classes. (Anonymous questionnaire)

However, students were often less certain of the forms of participation and contribution that were associated with the module:

I was not expecting to have to write weekly reflections. It was very intimidating. (Blog 10)

I found the task of setting up my own blog quite daunting as it isn't something I ever considered doing. It is a style of writing that I am not used to but being able to read each other's blogs and learn from what they have done is something I found invaluable. (Blog 44)

The digital learning approach employed for the module placed a strong emphasis on students' active input. This redefined students' engagement with the module not only through space, but also through time, as participation in it was not limited to scheduled classes. This difference in the organisation of learning - in relation to other modules - was often regarded as an interference with students' established study routines, as reflected by some participants where their lack of participation was concerned:

The University requires that we as full time students have a specific number of contact hours. (...) [but] this module was always on. (Anonymous questionnaire)

People focused on their blog posts in between classes and on their other coursework for other modules which left no time to interact online in between classes. (Anonymous questionnaire)

Digital forms of participation and education not only impose a constant engagement with what is being learnt, but they also render a higher level of exposure and visibility. Learning online entails regular and observable forms of contribution as a form of establishing a presence and evidencing engagement with learning. These were aspects of digital participatory learning that many students found difficult to engage with as their learning practices seemed to be better adjusted to standardised modules in which the process of learning is more often than not a private activity rather than a public one.

Notwithstanding the lack of sustained online activity in between scheduled classes as part of their engagement with the module, students reported that they felt more at ease engaging with online formats than they did participating in face-to-face classes, as depicted in the following section. As Barak, Boniel-Nissim, and Suler (2008) assert, "it is well known that people say and do things in cyberspace that they ordinarily would not say or do in the face-to-face world” (p. 1870). In our case this difference in behaviour is not in any way pernicious. In fact, it evidences what Suller (2004) would call a positive disinhibition effect that generates interactions between peers and tutor as part of the learning experience. Nonetheless, it is unclear if this form of performance endows students with a sense of personal empowerment as their online participation is mostly limited to scheduled classes, thus not fulfilling one of the key objective of critical education, that is, unhampered participation (Illich, 1971).

\section{Online learning as exposure}

In general, students were enthusiastic about the online sessions offered as part of the module. They reflected that online sessions:

worked more effectively as I felt I could voice my opinions easily. (Anonymous questionnaire)

[were] much easier as you feel your opinion and comments matter more, no one is there to scrutinise you. (Anonymous questionnaire)

Such statements were particularly justified because of the degree of reassurance the online medium provided to students when engaging with both the lecturer and their peers. This type of evidence was made clear via the online questionnaire, where students were asked to reflect on their participation in the course: 
I feel more confident in speaking out online rather than in class. (Anonymous questionnaire)

You have more confidence to speak over twitter as the boundaries are blurred and I felt much more comfortable to ask questions and answer questions via twitter. (Anonymous questionnaire)

The connection of online participation with a strong sense of confidence provides some insights into the perceptions of power structures that may be associated with classic classroom dynamics between students and tutors. The online world is often regarded as a space where participation can be developed in democratic ways (Dahlberg, 2001) and where confidence is enacted through a perception of status neutralisation (Barak et al., 2008). This may well be because of the lack of physical contact or a disembodied imagination of their social position within this type of learning experience. Such perceptions can lessen the sense of authority some individuals may convey in relation to others when playing different roles as part of an educational experience. As a space of socialisation, the Web may convey a more diluted version of power dynamics and thus suggest a certain sense of parity where individuals regard each other as participants rather than students and tutors.

Another aspect regarding online participation that we can consider here relates to the observation that digital forms of communication provide users with time and space for reflection as opposed to requiring an immediate reaction. This feature is often preferred by introverts (Myers \& Myers, 1980) who enjoy the sense of distance the screen seems to imply:

Contributing online gives you the time to properly think about your answer and compose it the way you want. It is also less intimidating sending an answer on Twitter (...) it doesn't feel as much of a big deal [when compared to] contributing an answer in front of the lecturer and the whole class (Anonymous questionnaire)

Hence, online participation can be regarded as a safe space in that it can provide individuals with a certain degree of visibility as well as forms of participation that are more conducive to introvert dispositions. Moreover, research points out that introverts may find 'their real me' more easily online (Amichai-Hamburger, Wainapel, \& Fox, 2002) because of the different forms of expression that the Web enables:

I prefer online as I am shy and therefore felt I could participate more online. (Anonymous questionnaire)

Nonetheless, contributions to online discussions seem to be regarded by students more as a form of class participation, or presence, rather than a form of empowerment and autonomy to learn. Research field notes confirm that:

Students seem to feel more comfortable contributing to the discussion online [...]they are quite 'at home' contributing to the class discussion via Twitter, often asking for more questions to be asked during the session as an opportunity for participation. However, this interaction, which amounts to hundreds of tweets in one single session, soon dies out once the session is over. Online interactions only seem to happen during class time. (Researcher 1 , field notes)

This last observation by the researcher seems to be justified by one of the participants who states that the:

Lack of online interaction [between classes] is possibly because people didn't feel the need to and thought they could slip under the radar. (Anonymous questionnaire)

We can herein infer that although the Web provides individuals with new forms of expression, it does not automatically endow students with a sense of agency. In the presence of formal education requirements, the tutor still holds a distinctive position within the educational hierarchy: 
I think people [the other students] might have been hesitant to start a discussion/interaction between classes because they hadn't seen anyone else post anything besides the lecturer. (Anonymous questionnaire)

The Web may blur boundaries, but it does not obliterate them completely. These become ever more pronounced when individuals realise that their contributions online are observable:

A possible reason [why people did not participate between classes] was that people may have been unsure of their answers and therefore were unsure what to comment out in the open. (Anonymous questionnaire)

It was the first time that my course work was made public. Although I enjoyed the experience, I felt exposed. (Anonymous questionnaire)

The example quotes used above show that online communication can work in favour of students' participation in that it provides them with a platform for exploration of their own voice. Nonetheless, online communication, as a performative act - as a process of becoming part of that environment - is also a form of exposure that students prefer to experience in more cautious ways because of the visibility it provides. The Web as a locus of participation is not only a space where students can develop their voice, but also a place where their contribution can be open to scrutiny.

Participants' enthusiasm for a digital participatory approach as part of their learning derives from the uniqueness of the approach proposed. However, this novelty is soon replaced by confusion as to their role as learners and the way their learning should be conducted.

The perceptions participants shared about being able to more freely develop a voice online than face-toface is a curious finding. They seem to be caught between the public-private dilemma the Web presents to its users. In this regard, the Web as a stage for learner participation seems, at first sight, to enhance students' participation more than it disrupts. However, the visibility developed on the Web also leads to a greater sense of vulnerability given the exposure inherent to the publication of ideas online. Even though participants' contributions may be seen as disembodied - in the absence of physical bodies - their voices are not, because their participation is not anonymous. The lack of anonymity can ensue internal conflicts regarding the responsibility that is implicitly placed on participants' contributions as an example of critical learning. This raises the question of whether the Web has, in the context of this study, been used and regarded by students as a tool of power or empowerment.

Following this analysis of the research data, we will now engage in a critical discussion of the findings. We start by employing the work of Bourdieu $(1990,2000)$ and where his work presents shortcomings we will employ the work of other theorists to provide a more encompassing reflection on the findings.

\section{Discussion}

The purpose of critical education is that of liberating the learner, in other words, of providing them with the tools and attitudes to take ownership of their learning as they become informed citizens. This is according to Freire and his followers (see, for example, Apple, 2013; Giroux,1998) the ultimate purpose of education. The combination of critical education principles with a digital participatory culture implies the development of curricular strategies that allow learners to transform their online participation into meaningful acts of learning (Illich, 1971, p. 44). The Freirean problem-posing method (Freire, 1968/1970) does not differentiate between the activity of the teacher and that of the student, which in Irwin's view means to have “doxa (opinion) superseded by logos (knowledge)" (2012, p. 58). The transformation of doxa into knowledge has the purpose of developing agents' critical consciousness (Shor \& Freire, 1987, p. 87) as part of their engagement with the social world and their education. Additionally, the goal of this transformation is also that of changing agents' status from recipients to creators of information as a form of agency. Critical participation epitomises one of the main principles of digital education. Even though the Web as a space of individual and collective participation provides the tools and spaces for that transformation to happen, technology alone cannot lead to individual emancipation. There are a series of socio-economic, cultural and institutional factors that also come into play. 
In the case of our study it was particularly visible that participants were not ready to fully change their learning practices from consumers to producers of knowledge. Students showed a learning habitus typical of more conventional teaching and learning relationships which are often punctuated by a specific time and place as part of an academic routine that has historically gained universal acceptance (Bourdieu, 2000, p. 88), that is, its taken-for-granted structure. This doxified approach further meant that participants strategically - but perhaps unconsciously - adjusted their learning practices to follow what they perceived to be the rules of the module as if it were a game in which they played. More specifically, students focused particularly on activities that counted towards their learning credits and which carried the weight of assessment. Unsurprisingly, students organised their practice to comply with assessment activities, for example, the writing of weekly blogposts. Yet, they showed far less commitment in participating online for the purpose of the module between scheduled classes.

Although the blogging activities can be regarded as forms of participation and production of knowledge and indeed they are forms of knowledge contribution - it was perceptible that students' engagement in such proposed practices was a direct and strategic response to curricular activities validated by assessment rather than a step towards autonomous learning. As Bourdieu (1991) reminds us, "by virtue of the habitus, individuals are already predisposed to act in certain ways, pursue certain goals, avow certain tastes” (p. 17). Changing those predispositions takes more than a new proposal of practice. It requires a greater awareness of the taken for granted approaches and which Freire (1968/1970, p. 74) called critical "conscientização". Without evidence of this level of conscious action as a form of empowerment- which we did not find in our research - we can never adequately interpret participants' actions as premeditated, precisely because their practices are conducted in the silence of the doxa (Bourdieu, 1991, p. 131).

Students' doxic approach prevented them from fully developing a sense of agency that matched the imperatives of a digital participatory culture. The logic of practice proposed for this module established a clear difference in relation to the practices students have developed as part of their studies in other modules. Such difference in practice became a hidden barrier to participants' adoption of participatory approaches to their studies. It is important to note that this unconscious resistance to online participation does not seem to be a reflection or lack of appropriate literacies to learn on the Web. It is rather a reflection of participants' learning habitus and their strategic understanding of how academia generally works.

Students' investment in the academic game implies a good knowledge of the rules of the field of academia as well as the role they play in it, in other words, their status. In our particular case, it is the academy and not the Web that regulates participants' studies. It is therefore no surprise that their learning habitus is more oriented towards the dominant ways of playing the game than it is towards the opportunities the Web presents for learning in a more autonomous way. Logics of practice "are defined in the relationship between habitus and objective structures inherited from history” (Bourdieu, 1998, p. 53). Academia thus overrules the Web as a space of learning because of its long tradition and its legitimate power (Costa, 2013). The result is a preference for following the rules assumed to belong to the academy as they provide students with a stable structure of practice that is known to them and which they have learnt to navigate. This familiarity with the rules of the game provides students with a higher degree of reassurance regarding the approaches they take. Bourdieu (1990) names this "illusio" - "the tacit recognition of the stakes of the game” (p. 110). It is this recognition of the value of the game that drives participants to invest in what they regard as appropriate or adequate practices and to avoid activities that lie outside the norm and which can therefore be regarded as a risk or diversion. Motivating this approach is a false sense of control over the rules of the game which if carried out successfully are expected to yield a higher degree of academic recognition. The field of academia through its doxa indistinguishably exercises power over its actors and reifies illusio as achievement. The outcome is a classic example of reproduction of academic practices.

It would, however, be unfair to say that the Web as a field of knowledge production and participation did not generate any interest or change in the way students interacted and learnt in the module under investigation. The main purpose of the module was to raise awareness of different ways of learning through the participatory features the Web affords to its users. Even though participants felt it hard to sustain the learning interaction outside scheduled learning hours, online participation during class time was profuse, marking a distinctive difference in relation to interactions with the tutor and peers in face-to-face contexts. When students set aside time to participate online as part of the module they did so in "unhampered ways" (Illich, 1971), thus evidencing their capability for agency and dialogue. This discrepancy in relation to students’ participation outside class time is worth exploring and reflecting on. 
Borrowing from Foucault (1975/1991) the metaphor of the panopticon, we can devise an interpretation of the Web that reveals participants' engagement online in a less liberating light and from a more repressive position. Regarding the Web as a panopticon means to consider the Web as a surveillance tool of online behaviours. In our concrete case, the Web provides the tutor with access to students' online presence and participation in the context of their education. The effect of Web panopticism can thus be understood as a form of power that 'is visible in the form of the central watchtower' (Hope, 2013, p. 35) and which exposes the student, but covers the watcher.

The Web when regarded as a panopticon ceases to fulfil the purpose of an emancipatory learning experience, because it jeopardises the essence of critical agency, that is, autonomy. This interpretation can be inferred in our research through students' own ambivalence regarding the frequency, value and purpose they attach to their online contributions. The Web as a panopticon serves students well as a place of visible participation when that type of performance is needed, as, for example, participation during class time. Yet, Web panopticism becomes an obstacle to authentic participation because it also works as a space of control that brings to the fore students' status in the educational hierarchy, the status of learners under the gaze of the master, or tutor.

Viewing digital learning through the prism of panopticism inevitably invites a reference to the creation of “docile bodies” in education (Rabinow, 1984). The ways in which students in this study shape their learning experiences in strategic ways and navigate the observational aspects of digital environments certainly points to the disciplined and subjectified self-referenced in the literature (Cooper, 2014). At the same time, the level of ambivalence they exhibit towards their participation and online activity suggests a more nuanced picture of the strategic learner, one in which Bourdieu's (1990) illusio and the recognition of the rules of the game comes more to the fore. While the parameters of docility are open to question, such reference to subjectivation and doxa surely help to undermine the conception of digital learning as an unhindered and wilful transformative act.

\section{Implications for practice and policy}

A key objective of this study was to gather research evidence regarding higher education students' digital participatory learning practices in a formal setting. This has been achieved through the design of educational activities influenced by digital cultures and critical education principles and observations and accounts of students' engagement with such learning activities. The findings produced by this study are relevant to policy and practice in that they show how digital participatory learning practices are still atypical in academia, and that they will continue to be so unless curricular changes are made at programme and institution-wide levels.

This paper suggests that curricular changes in sporadic modules cannot overturn the tacit knowledge students have of the rules of the academic game and which become embodied learning practices. Even though students are no strangers to the Web, they do not necessarily connect their online participation with relevant forms of learning, because such practices are not identified within degree structures. Critical digital education can only be fully materialised in higher education if an effective curricular reform is conducted to recognise principles of digital culture in institutional curriculum frameworks. This requires more than institutions' adoption of technology or changes in the role of the teacher (Devlin \& McKay, 2016). It also implies the formal recognition of students' digital participation and knowledge productions as forms of learning and assessment. Further research in this area could thus explore:

- $\quad$ the type of professional learning necessary for the development of digital education curricula and practices

- $\quad$ the support students require to move from consumers to producers of knowledge

- $\quad$ the role of the institution in promoting digital participatory education.

\section{Limitations of the study}

The limitations of this study are related to the locus of the experiment that was restricted to one site of inquiry. Although the sample size was not particularly small, future research would benefit from a multiple research site approach featuring different curricular frameworks. 


\section{Conclusion}

The Web has become an ever-increasing presence and influence in practices of knowledge construction and consumption. There is a strong argument for it to be included in education as a form of linking the university to real-life practices. In this regard, the integration of digital practices into the curriculum becomes an imperative, one that should take into consideration the phenomenon the Web has become and the digital participatory practices that are therein emerging. Such proposal means to understand the Web beyond its technical function of providing access to information and to appreciate the contexts it enables for learner engagement and participation.

The recognition of the role of the Web as both a tool and space of participatory learning does not, however, lie solely on the teacher or the learner, but equally on the institution whose stable structure can become a hidden obstacle against curricular changes inspired by digital cultures. This is particularly visible in the current study, where participants do not necessarily regard their online participation as learning, but as a form of presence. Given the lack of bodily presence in online spaces, class attendance is evidenced by tangible forms of participation as a way of creating a sense of "being there” (Rettie, 2005, p. 22).

Hence, students' online engagement during class time could also be regarded as a performative act which inadvertently results in forms of participation, but not necessarily regarded as a form of empowerment. The Web as a panoptic space pays more and better service to power structures through the relationships that are established by agents with different status than it empowers learners with new spaces for critical learning. In this sense, the Web may seem to limit learners' actions more than it is able to liberate them in the context of formal education. This is precisely because the Web even though it can be considered as a space of democratic participation does not cancel out the power relationships that permeate the educational world. On the contrary, it can intensify them. An act of resistance against the panoptic eye is then a refusal to participate beyond the necessary, in order to keep a relevant position in the field of education.

\section{Acknowledgements}

Ana Lucia Pereira acknowledges the support from CAPES, Brazil (Grant n. 99999.000403/2016-04).

\section{References}

Angrosino, M. (2007). Doing ethnographic and observational research. London: Sage.

Amichai-Hamburger, Y., Wainapel, G., \& Fox, S. (2002). “On the Internet no one knows I'm an introvert”: Extroversion, neuroticism, and internet interaction. CyberPsychology \& Behavior, 5(2), 125-128. https://doi.org/10.1089/109493102753770507

Apple, M. W. (2013). Education and power. New York, NY: Routledge.

Barak, A., Boniel-Nissim, M., \& Suler, J. (2008). Fostering empowerment in online support groups. Computers in Human Behavior, 24(5), 1867-1883. https://doi.org/10.1016/j.chb.2008.02.004

Bennett, S., \& Maton, K. (2010). Beyond the 'digital natives' debate: Towards a more nuanced understanding of students’ technology experiences. Journal of Computer Assisted Learning, 26(5), 321-331. https://doi.org/10.1111/j.1365-2729.2010.00360.x

Bourdieu, P. (1977). Outline of a theory of practice. Cambridge: Cambridge University Press.

Bourdieu, P. (1989). Social space and symbolic power. Sociological Theory, 7(1), 14-25. https://doi.org/10.2307/202060

Bourdieu, P. (1990). The logic of practice. Stanford, CA: Stanford University Press.

Bourdieu, P. (1991). Language and symbolic power. (J. Thompson, Ed.; G. Raymond \& M. Adamson, Trans.). Cambridge, MA: Harvard University Press.

Bourdieu, P. (1998). The state nobility: Elite schools in the field of power. Cambridge, MA: Stanford University Press.

Bourdieu, P. (2000). Pascalian meditations. Cambridge, MA: Stanford University Press.

Bourdieu, P., \& Passeron, J. C. (1979). The inheritors: French students and their relation to culture. (R. Nice, Trans.). Chicago, IL: University of Chicago Press. (Original work published 1964)

Bourdieu, P., \& Passeron, J. (1990). Reproduction in education, society and culture (2nd ed.). London: Sage. 
Buckingham, D. (2013). Beyond technology: Children's learning in the age of digital culture. Cambridge: John Wiley \& Sons.

Burawoy, M., \& Holdt, K. V. (2012). Conversations with Bourdieu: The Johannesburg moment. Johannesburg: Wits University Press.

Castells, M. (2012). Networks of outrage and hope: Social movements in the Internet age. Chichester: Polity Press.

Clark, W., Logan, K., Luckin, R., Mee, A., \& Oliver, M. (2009). Beyond Web 2.0: Mapping the technology landscapes of young learners. Journal of Computer Assisted Learning, 25(1), 56-69. https://doi.org/10.1111/j.1365-2729.2008.00305.x

Cooper, P. (2014). Implications of the marketization of higher education for social emotional development in schools: A personal view. International Journal of Emotional Education, 6(2), 90-94. Retrieved from https://www.um.edu.mt/library/oar//handle/123456789/6222

Costa, C. (2013). The participatory web in the context of academic research: Landscapes of change and conflicts (Doctoral dissertation). Retrieved from http://usir.salford.ac.uk/28369/

Costa, C., \& Harris, L. (2017). Reconsidering the technologies of intellectual inquiry in curriculum design. The Curriculum Journal, 28(4), 559-577. https://doi.org/10.1080/09585176.2017.1308260

Costa, C., \& Murphy, M. (2016). Doxa, digital scholarship and the academy. In M. Murphy \& C. Costa (Eds.), Theory as method in research: On Bourdieu, education and society (pp. 49-62). Abingdon: Routledge.

Dahlberg, L. (2001). The Internet and democratic discourse: Exploring the prospects of online deliberative forums extending the public sphere. Information, Communication \& Society, 4(4), 615633. https://doi.org/10.1080/13691180110097030

de Freitas, S., \& Jameson, J. (2012). The e-learning reader. London: Continuum.

Devlin, M., \& McKay, J. (2016). Teaching students using technology: Facilitating success for students from low socioeconomic status backgrounds in Australian universities. Australasian Journal of Educational Technology, 32(1). https://doi.org/10.14742/ajet.2053

Dias de Figueiredo, A. (2005). Learning contexts: A blueprint for research. Digital Education Review, 11, 127-139. Retrieved from http://revistes.ub.edu/index.php/IEM/article/view/11803/1461

Duncan-Howell, J. (2012). Digital mismatch: Expectations and realities of digital competency amongst pre-service education students. Australasian Journal of Educational Technology, 28(5). https://doi.org/10.14742/ajet.819

Foucault, M. (1991). Discipline and punish: The birth of the prison. (A. Sheridan, Trans.). London: Penguin. (Original work published 1975)

Freire, P. (1985). The politics of education: Culture, power, and liberation. Westport, CT: Greenwood Publishing Group.

Freire, P. (1970). Pedagogy of the oppressed. New York, NY: Continuum. (Original work published 1968)

Giroux, H. A. (1988). Teachers as intellectuals: Toward a critical pedagogy of learning. Westport, CT: Greenwood.

Grønning, I. (2015). Being a good spy: Legitimizing access to web-based observation. Etikk i Praksis Nordic Journal of Applied Ethics, 9(2), 19-32. https://doi.org/10.5324/eip.v9i2.1864

Hope, A. (2013). Foucault, panopticism and school surveillance research. In M. Murphy (Ed.), Social theory and education research: Understanding Foucault, Habermas, Bourdieu and Derrida (pp. 3551). London: Routledge.

Hrastinski, S., \& Aghaee, N. M. (2011). How are campus students using social media to support their studies? An explorative interview study. Education and Information Technologies, 17(4), 451-464. https://doi.org/10.1007/s10639-011-9169-5

Illich, I. (1971). Deschooling society. New York, NY: Marion Boyars Publishers Ltd.

Irwin, J. (2012). Paulo Freire's philosophy of education: Origins, developments, impacts and legacies. New York, NY: Bloomsbury.

Jenkins, H. (2009). Confronting the challenges of participatory culture: Media education for the 21st century. Cambridge, MA: MIT Press.

Jenkins, H., Ito, M., \& boyd, d. (2016). Participatory culture in a networked era: A conversation on youth, learning, commerce, and politics. Cambridge, MA: Polity Press.

McLoughlin, C. E. (2013). The pedagogy of personalised learning: Exemplars, MOOCS and related learning theories. In J. Herrington, A. Couros, \& V. Irvine (Eds.), Proceedings of EdMedia 2013. World Conference on Educational Media and Technology (pp. 266-270). waynesville, NC: 
Association for the Advancement of Computing in Education. Retrieved from https://www.learntechlib.org/p/111968/

Miller, V. (2011). Understanding digital culture. Los Angeles, CA: Sage.

Myers, I. B., \& Myers, P. B. (1980). Gifts differing: Understanding personality type. Palo Alto, CA: Davies-Black.

O'Reilly, T. (2005). What is Web 2.0: Design patterns and business models for the next generation of software. Retrieved from http://oreilly.com/web2/archive/what-is-web-20.html

Rabinow, P. (Ed.). (1984). The Foucault reader. New York, NY: Pantheon.

Rettie, R. M. (2005). Presence and embodiment in mobile phone communication. PsychNology Journal, $3(1), 16-34$.

Selwyn, N. (2011). Education and technology: Key issues and debates. London: Continuum.

Shor, I., \& Freire, P. (1987). A pedagogy for liberation: Dialogues on transforming education. Westport, CT: Greenwood.

Sharpe, R., Beetham, H., \& de Freitas, S. (2010). Rethinking learning for a digital age: How learners are shaping their own experiences. New York, NY: Routledge.

Tacchi, J., Foth, M., \& Hearn, G. N. (2009). Action research practices and media for development. International Journal of Education and Development using Information and Communication Technology, 5(2), 32-48. Retrieved from http://ijedict.dec.uwi.edu/include/getdoc. php? $i d=4374 \&$ article $=560 \&$ mode $=$ pdf

Tacchi, J., Slater, D., \& Hearn, G. (2003). Ethnographic action research: A user's handbook. New Delhi: UNESCO. Retrieved from http://unesdoc.unesco.org/images/0013/001394/139419eo.pdf

Waycott, J., Bennett, S., Kennedy, G., Dalgarno, B., \& Gray, K. (2010). Digital divides? Student and staff perceptions of information and communication technologies. Computers \& Education, 54(4), 1202 1211. https://doi.org/10.1016/j.compedu.2009.11.006

Wenger, E., White, N., \& Smith, J. D. (2009). Digital habitats: Stewarding technology for communities. Portland, OR: CPsquare.

Corresponding author: Cristina Costa, Cristina2.Costa@uwe.ac.uk

Australasian Journal of Educational Technology @ 2018.

Please cite as: Costa, C., Murphy, M., Pereira, A. L., \& Taylor, Y. (2018). Higher education students' experiences of digital learning and (dis)empowerment. Australasian Journal of Educational Technology, 34(3), 140-152. https://doi.org/10.14742/ajet.3979 